\title{
As redes de inovação sob a premissa do comunitarismo: ambientes para geração da inovação tecnológica na universidade
}

\author{
João Pedro Schmidt 1 \\ Isabel Grunevald ${ }^{2}$
}

\begin{abstract}
Resumo: Este trabalho apresenta um olhar sobre a criação de novas tecnologias, caracterizadas através da inovação tecnológica na atual sociedade do conhecimento, observando-se se tal alcance está alinhado aos preceitos fundamentais da teoria filosóficapolítica do comunitarismo responsivo. O comunitarismo destaca o equilíbrio entre Estado-comunidade-mercado, como modelo alternativo à dicotomia público/privado. Trata-se de um estudo inicial, no qual parte-se do pressuposto que a inovação tecnológica é fruto de um processo de construção coletiva, e não decorrendo de iniciativas individuais. A base teórica do presente texto no que tange ao comunitarismo está inclinada às obras de Amitai Etzioni e o método é o bibliográfico.
\end{abstract}

Palavras-chave: Comunitarismo Responsivo; Inovação tecnológica; Redes de inovação.

The Networks Of Innovation About The Communitarianism Premises: Environments For The Generation Of Technological Innovation In The University

\begin{abstract}
This work presents a look at the creation of new technologies, characterized by technological innovation in the current knowledge society, observing if such reach is aligned with the fundamental precepts of the philosophical-political theory of responsive communitarianism. Communitarianism highlights the balance between the statecommunity-market as an alternative model to the public/private dichotomy. This is an initial study, in which it is assumed that technological innovation is the result of a process of collective construction, and not from individual initiatives. The theoretical basis of the present text regarding communitarianism is inclined to the works of Amitai Etzioni and the method is the bibliographical.
\end{abstract}

Keywords: Responsive communitarism; Tecnological innovation; Innovation networks.

Las Redes De Innovación Sob Las Premisas Del Comunitarismo: Ambientes Para Generar Innovación Tecnológica En La Universidad

Resumen: Este trabajo presenta una mirada a la creación de nuevas tecnologías, caracterizadas a través de la innovación tecnológica en la atual sociedad del conocimiento, observando si dicho alcance está en línea con los preceptos fundamentales de la teoría filosófico-política del comunitarismo responsable. El comunitarismo destaca el equilibrio entre Estado-comunidad-mercado, como modelo alternativo a la dicotomía

\footnotetext{
${ }^{1}$ Mestre em Direito e Doutoranda em Tecnologia Ambiental com ênfase em informação tecnológica pela Universidade de Santa Cruz do Sul (UNISC). Coordena o Núcleo de Inovação e Transferência de Tecnologia da mesma Universidade. Professora do curso de Direito da Faculdade Antonio Meneghetti. jpedro@unisc.br ${ }^{2}$ Doutorado em Ciência Política pela Universidade Federal do Rio Grande do Sul. Pós-doutorado na The George Washington University, Wasghinton DC. Mestrado em Filosofia pela Universidade Federal do Rio Grande do Sul (UFRGS). Graduação em Filosofia pela Faculdade de Filosofia Imaculada Conceição (FAFIMC). Professor titular da Universidade de Santa Cruz do Sul. isabelgru@ hotmail.com
} 
público / privado. Se trata de un estudio inicial, en el que se asume que la innovación tecnológica es el resultado de un proceso de construcción colectiva, y no de iniciativas individuales. La base teórica de este texto con respecto al comunitarismo se inclina por los trabajos de Amitai Etzioni y el método es bibliográfico.

Palabras clave: Comunitarismo Responsable; Innovación tecnológica; Redes de innovación.

\section{Introdução}

Vive-se atualmente a chamada "Era do conhecimento" e isso está consolidado. Nunca as pessoas tiveram tanta importância no processo de desenvolvimento tecnológico, que emerge da necessidade constante de aperfeiçoar tecnologias já existentes, buscando melhorias em produtos, processos ou serviços, criar tecnologias e inovar.

Para criar um ambiente favorável e estimular o desenvolvimento de novas tecnologias, o governo brasileiro tem na última década apresentado uma série de políticas públicas de incentivo à ciência, à tecnologia e à inovação, que visam ao estímulo e criam condições favoráveis ao seu desenvolvimento. Com o avanço da ciência e da tecnologia que se têm hoje, percebe-se apenas em poucos (ou quase inexistentes) casos que a inovação irá aflorar sem antecedentes, por isso, tem-se no viés comunitarista uma importante corrente para este avanço.

A corrente filosófico-política do comunitarismo, em especial o comunitarismo responsivo, prevê justamente um olhar colaborativo para as criações intelectuais, onde se encontram os componentes da tríade - Estado, mercado e comunidade - em sintonia.

O presente trabalho possui como objetivo a busca de pontuações teóricas acerca da inovação tecnológica no Brasil, ressaltando-se o comunitarismo responsivo como corrente para o desenvolvimento tecnológico e, por fim, um olhar sobre as universidades comunitárias com seus ambientes como integrantes de redes de inovação. Faz-se necessário ressaltar que se trata de um estudo inicial e o tema aqui proposto para reflexão tem espaço e necessidade de profundos e amplos debates.

\section{Da sociedade do conhecimento à inovação tecnológica no Brasil}


A sociedade do conhecimento ${ }^{3}$ criou um novo contexto que fez emergir um novo processo denominado de inovação. O que recentemente se resumia em políticas públicas ${ }^{4}$ de ciência e tecnologia, hoje forma o complexo de Ciência, Tecnologia e Inovação, ressaltando a importância e a ligação direta entre os três segmentos. Diversas são as conceituações terminológicas acerca da inovação, onde tem-se no Manual de Frascati como sendo:

[...] o conjunto de diligências científicas, tecnológicas, organizacionais, financeiras e comerciais, incluindo o investimento em novos conhecimentos, que realizam ou destinam-se a levar à realização de produtos e processos tecnologicamente novos e melhores. (OCDE, 2013, p. 23)

Para o Ministério das Comunicações, a inovação tecnológica é "toda a novidade implantada pelo setor produtivo, por meio de pesquisas ou investimentos, que aumenta a eficiência do processo produtivo ou que implica em um novo ou aprimorado produto". (BRASIL, 2015) Já a Associação Nacional de Entidades Promotoras de Empreendimentos Inovadores - ANPROTEC define a inovação como:

Introdução no mercado de produtos, processos, métodos ou sistemas não existentes anteriormente, ou com alguma característica nova e diferente daquela até então em vigor, com fortes repercussões socioeconômicas", e a inovação tecnológica como "introdução de produtos e processos tecnologicamente novos ou aprimorados. (2002, p. 62)

Por fim, o Manual de Oslo, que complementa o referencial básico mundial em termos de inovação, constituindo-se na "principal fonte internacional de diretrizes para coleta e uso de dados sobre atividades inovadoras da indústria" (OCDE, 2004, p. 5), define dois tipos de inovação tecnológica: (i) Inovação tecnológica de produtos (que se relaciona à produção de bens ou a serviços novos, podendo estes serem originalmente novos ou decorrendo da combinação de conhecimentos previamente existentes) e (ii) Inovação tecnológica de processos (relacionado a novas metodologias ou que apresentem significativa melhora, cuja aplicação pode decorrer tanto de ações no processo como no produto final). (OCDE, 2004, p. 55-56)

\footnotetext{
${ }^{3} \mathrm{O}$ termo "Sociedade do conhecimento" surge na década de 90 e é "empregado particularmente pelos meios acadêmicos, como alternativa à visão de mercado adotada pelos organismos econômicos mundiais". Alguns autores como Bell e Bursch utilizam a terminologia "Sociedade da Informação" e fazem referência ao processo de conhecimento; outros, como Drucker e Castells, falam em "Sociedade do Conhecimento" e em "Sociedade em Rede". Utiliza-se aqui o termo "Sociedade do Conhecimento" por entender, assim como os autores, que esta sociedade é "a sociedade em que o conhecimento se encontra ao alcance de todos que o desejarem". (DZIEKANIAK; ROVER, 2011)

${ }^{4}$ Por políticas públicas entende-se aqui ações, diretrizes e legislações criadas pelo governo federal brasileiro para dar conta de atender ao desenvolvimento da pasta criada em março de 1985.
} 
Neste cenário, onde o processo de criação e desenvolvimento torna-se essencial para o processo da inovação, tem-se como o recurso econômico básico desse novo ambiente social o o conhecimento, cujo principal motor, para Richard Florida (2011), é a criatividade. Conhecimento e informação são as ferramentas e os materiais para a criatividade, alcançando a inovação como produto final. A sociedade do conhecimento está essencialmente ligada à inovação e à economia do conhecimento. Deste modo, a inovação é uma questão de conhecimento, de criação de "novas possibilidades por meio da combinação de diferentes conjuntos de conhecimento". (TIDD; BESSANT; PAVITT, 2008, p. 35)

O termo inovação nunca esteve tão em pauta como na última década, porém equivocadamente acabou popularizando-se para uso de forma generalizada. Deve-se compreender que está diretamente ligada ao emprego do termo a concepção de algo novo, o que não é verdade absoluta, uma vez que a característica de novidade não é premissa para inovação. A inovação configura-se a partir da aceitação de alguma mudança por parte de determinado grupo ou parcela da sociedade. Assim, é possível ter-se um produto novo, por exemplo, que não seja inovador, pois não houve interesse do mercado em adquiri-lo ou absorvê-lo. A inovação é o motor da economia do conhecimento.

A discussão sobre a economia do conhecimento reflete-se também sobre o debate acerca da inovação sob seu viés tecnológico. Aqui, segundo Albagli e Maciel (2004, p. 11), "valoriza-se não apenas o conhecimento formalizado e dito avançado (conhecimento científico-tecnológico), mas também o conhecimento não formalizado, construído nas práticas econômicas e socioculturais", incluindo-se conhecimentos gerados a partir de organizações públicas ou privadas e mesmo de comunidades ou povos tradicionais.

Para Tidd, Bessant e Pavitt (2008, p. 72), o processo de inovação exige "lidar com uma fronteira científica móvel e em desenvolvimento, mercados fragmentados espalhados por todo o planeta, incertezas políticas, regulamentações instáveis”, onde a resposta para o atual sistema é o aprendizado para o gerenciamento da inovação em rede, buscando "um amplo conjunto de sinalizadores do conhecimento".

Emerge-se a necessidade de se buscar uma proteção para a inovação tecnológica, enquanto "exigência socioeconômica, sendo estreita a relação entre o progresso industrial de um Estado e a observância das legislações sobre patentes de invenção e sua adequação aos tratados internacionais". (BOFF; TEIXEIRA, 2011, p. 625) Deste modo, não basta que o processo inovador seja desenvolvido, se faz necessários mais, como a proteção das criações através das políticas de desenvolvimento econômico existentes. 
Mattos e Guimarães (2005, p. ix) defendem que para vencermos os desafios deste século, buscando o desenvolvimento da ciência e da tecnologia, onde pressupõe-se a presença da inovação e da criatividade, deve-se basear em três características fundamentais:

\begin{abstract}
A primeira delas se deve à existência do cérebro humano e ao incentivo à sua potencialidade; a segunda pode ser localizada na mobilização das pessoas e instituições em torno de objetivos, de bandeiras, de metas geradoras de algum benefício estratégico ou social; a terceira fase refere-se ao esforço nacional, canalizando recursos adequados para a área cientifica e tecnológica.
\end{abstract}

Historicamente ciência e tecnologia tiveram caminhos diversos, enquanto a ciência preocupava-se com assuntos acadêmicos, a tecnologia residia na preocupação do segmento industrial. Neste contexto, cada local ou região possui diferentes capacidades de produzir conhecimento, aprender ou mesmo inovar, que são influenciadas entre outras coisas por “combinações de características e bens coletivos - físicos, sociais, econômicos, culturais, políticos, institucionais. (ALBAGLI; MACIEL, 2004, p. 11) Observa-se que para Boff e Teixeira (2011, p. 632), "o mote é a inovação, a produção de pesquisas associada ao impulso na transferência de todo este conhecimento para produtos e serviços que melhorem a qualidade de vida da sociedade."

Quando se refere ao nível do Brasil em termos de desenvolvimento para a inovação, segundo dados do "The Global Innovation Index 2015”, cujo objetivo foi avaliar as efetivas políticas de inovação para o desenvolvimento, ocupamos a $70^{\circ}$ posição entre 141 países avaliados. Quando o olhar é sobre os países da América Latina e Caribe, passa-se a ocupar a 9 posição. Relativo ao "The Global Innovation Index 2016”, o país obteve uma melhora, uma vez que alcançou a posição $69^{\circ}$ em um universo maior de indicadores, e ocupando a $7^{\mathrm{a}}$ posição entre os países da América Latina e Caribe.

No Brasil, os dados oficiais são oriundos da Pesquisa de Inovação (PINTEC), que tem por objetivo a construção de indicadores setoriais nacionais e regionais das atividades de inovação das empresas brasileiras, comparáveis com as informações de outros países. (IBGE, 2015) Segundo dados do PINTEC, cuja ulterior análise ocorreu em 2011, teve-se no Brasil 45.950 empresas que implementaram alguma inovação, seja através de produtos ou processos, das quais, 4.902 estavam localizadas no Rio Grande do Sul.

Países em desenvolvimento, como o Brasil, precisam impulsionar a inovação tecnológica através de políticas públicas de incentivo e promoção. Neste sentido, o 
Ministério de Ciência, Tecnologia e Inovação vem atuado na construção, implantação e consolidação de bases legais para a inovação tecnológica.

O tema, incluindo o escopo geral das políticas públicas para a área - Ciência, Tecnologia e Inovação - encontra recepção na Carta Magna, em seu capítulo VII, referente à Ordem Social, e prevê, expressamente em seu artigo 218: "O Estado promoverá e incentivará o desenvolvimento científico, a pesquisa, a capacitação científica e tecnológica e a inovação". Complementado pelo $\S 1^{\circ}$ do mesmo artigo, ressalta-se a responsabilidade de o Estado em dar tratamento prioritário ao tema, visando especialmente ao "progresso da ciência, tecnologia e inovação".

Destacam Boff e Teixeira (2011, p. 624), nesta lógica, que “é obrigação do Estado, imposta constitucionalmente, o incentivo a atividades que possam gerar inovações tecnológicas, uma vez que só com a pesquisa tecnológica e científica é que essas ocorrerão".

Utilizando-se de um amplo debate com diferentes agentes que envolvem o Estado, a sociedade e o mercado, o Ministério de Ciência, Tecnologia e Inovação criou um marco regulatório sobre inovação tecnológica, organizando-o a partir de três linhas principais: "a constituição de ambiente propício às parcerias estratégicas entre as universidades, institutos tecnológicos e empresas; estímulo à participação de instituições de ciência e tecnologia no processo de inovação; e incentivo à inovação na empresa.” (BRASIL, 2015).

\footnotetext{
O desafio de se estabelecer no país uma cultura de inovação está amparado na constatação de que a produção de conhecimento e a inovação tecnológica passaram a ditar crescentemente as políticas de desenvolvimento dos países. Nesse contexto, o conhecimento é o elemento central das novas estruturas econômicas que surgem e a inovação passa a ser o veículo de transformação de conhecimento em riqueza e melhoria da qualidade de vida das sociedades. (BRASIL, 2015)
}

Inúmeras são as leis brasileiras relacionadas à inovação. Cabe especial destaque à chamada Lei de Inovação, de $n^{\circ} 10.973$, de 2 de dezembro de 2004, cujo objetivo foi criar condições para um cenário favorável ao desenvolvimento científico, tecnológico e ao incentivo à inovação. A referida lei está organizada para atender três linhas centrais, quais sejam: criação de um ambiente propício a parcerias estratégicas entre representantes do setor público, privado e mercado - aqui se enquadra a possibilidade da criação de redes para o desenvolvimento de projetos cooperativos, além de ambientes para estimular o processo de inovação, tais como incubadoras de empresas e parques tecnológicos, por exemplo; estimulo à participação de instituições de ciência e tecnologia no processo de inovação; e incentivos à inovação nas empresas. 
Ademais existem outras previsões legais tais como a Lei do Bem e a Lei de Informática, que abordam o tema e completam o escopo de políticas públicas voltadas à inovação tecnológica, porém não são objeto de análise neste trabalho.

Schmidt (2008, p. 2309), aponta que:

A análise das políticas públicas não pode ser feita de forma fragmentada nem isolada da análise mais geral sobre os rumos do Estado e da sociedade. As políticas não são uma espécie de setor ou departamento com vida própria. Elas são o resultado da política, compreensíveis à luz das instituições e dos processos políticos, os quais estão intimamente ligados às questões mais gerais da sociedade.

No caso brasileiro, o que se percebe é que as políticas públicas vigentes têm se preocupado com a busca e com o incentivo da aproximação dos diferentes agentes que possuem vínculo com a temática, tais como Governo, Universidades e Empesas. Essa aproximação é fundamental, pois

Um dos fatores do êxito ou fracasso das políticas públicas é a articulação entre o momento da formulação e da implementação. O entendimento compartilhado dos objetivos e das metas das políticas depende em boa parte do entrosamento e de conhecimentos comuns entre formuladores e implementadores, bem como da participação dos implementadores no momento da formulação. (SCHMIDT, 2008, p. 2318)

Cooperação e interação têm se tornado uma ideia amplamente aceita: "a importância desse trabalho em rede não fica restrita à relação empresa/empresa - é também uma questão de criar vínculos valiosos dentro do sistema nacional de inovação". (TIDD; BESSANT; PAVITT, 2008, p. 74) Hoje, o Brasil, embora possua todos os requisitos para tal, não possui um eficiente e definido Sistema Nacional de Inovação, que caracterize de forma eficiente as articulações necessárias básicas entre os agentes da tríplice hélice - Estado, Universidades e Empresas.

No dizer de Tomaél (2008, p. 4), a articulação dos membros da tríplice hélice é condição para o fortalecimento dos fluxos de conhecimento que estão focalizados em campos tecnológicos novos, especialmente entre as organizações pertencentes a arranjos territoriais, tais como incubadoras e parques tecnológicos.

A mobilização de redes de inovação vem, nos últimos anos, se constituindo no propósito central das políticas de C\&T dos países avançados e dos países que vêm empreendendo grande esforço de articulação de suas políticas de C\&T e inovação. Essas redes vêm contribuindo para a compreensão do enfoque sistêmico do complexo processo de inovação. (CGEE, 2006, p. 38) 
As conexões de um sistema de inovação podem se dar de forma local, regional ou nacional, e sua composição e funcionamento podem variar de acordo com as necessidades a que se propõem. Tidd, Bessant e Pavitt (2008, p. 91) definem que "Por sistema de inovação, entendemos a gama de participantes [...] que representam o contexto dentro do qual as organizações operam seus processos de inovação". Assim, os sistemas de inovação podem ser vistos enquanto redes que se formam, vinculadas a uma determinada localidade com indivíduos que possuem interesses em comum.

\section{O viés comunitarista sustentado pela tríade: Estado, comunidade e mercado}

As redes permitem aos seus integrantes a interação e o desenvolvimento conjunto. Assim, em uma ótica semelhante à do tríplice hélice - onde tem-se a articulação entre governo, universidade e empresa - este estudo se orienta pelo viés comunitarista, com destaque à ideia do equilíbrio entre Estado, comunidade e mercado.

O comunitarismo é uma corrente filosófica-política e "pode ser definido como um ideário que confere centralidade à comunidade (e não ao Estado ou ao mercado)". (SCHMIDT, 2014, p. 93-94) O presente trabalho irá pontuar algumas questões a partir do pensamento do sociólogo Amitai Etzioni, que iniciou seus estudos abordando temas de sociologia organizacional, porém a partir da década 90 tornou-se defensor do modelo comunitarista.

O comunitarismo responsivo ${ }^{5}$ desenvolveu-se por Etzioni com a participação de outros intelectuais, originando-se a partir da plataforma The Responsive Communitarian Platform: Rights and Responsibilities, onde destaca-se especialmente a importância da presença e da atuação da comunidade no contexto social. (SCHMIDT, 2014, p. 101-102) Acrescenta Cervi (2013, p. 156) que se trata de uma terceira via para as demasias do Estado e do mercado, propondo de forma inovadora a valorização da comunidade para suprir as deficiências dos modelos clássicos de gestão. Este comunitarismo busca o equilíbrio entre os direitos individuais e as responsabilidades sociais, entre o indivíduo e a comunidade, assim como entre a autonomia e a ordem social. (ETZIONI, 1999)

\footnotetext{
${ }^{5}$ O termo responsivo, explica Etzioni (1998; 2003), foi escolhido para explicitar a preocupação dos comunitaristas em dar respostas às pessoas, em serem sensíveis aos anseios do povo e deixar clara sua diferença tanto em relação aos comunistas como aos comunitários autoritários do Leste Asiático. (SCHMIDT, 2014, p. 101-102)
} 
Corroborando com a corrente exposta, Costa e Silva (2011, p. 567) destacam que em virtude do atual "território da democracia, o direito, seus procedimentos e as instituições começam a ser mobilizados em torno da cooperação e da solidariedade social, apontando para a construção de um espaço em que se verifiquem os pressupostos do comunitarismo". Os pressupostos do comunitarismo encontram recepção no texto da Constituição Federal. Schmidt e Araujo (2012, p. 337) destacam que "um dos temas mais caros ao comunitarismo: o da relação equilibrada entre Estado, comunidade (sociedade) e mercado" foi recepcionado na Carta Magna.

A Constituição de 1988 não tende nem ao estatismo nem ao privatismo. $\mathrm{O}$ paradigma do Estado de Bem-Estar está claramente presente na Carta Constitucional. Subjaz à Constituição a concepção de um Estado forte, protetor dos cidadãos, economicamente ativo e regulador do mercado. A Constituição é enfática quanto à ênfase na cooperação entre Estado e sociedade na garantia dos direitos sociais e reconhece a participação da sociedade na execução das políticas sociais: saúde (artigo 197), assistência social (artigo 204), educação (artigo 205), cultura (artigo 216), desporto (artigo 217), meio ambiente (artigo 225), comunicação social (artigo 223). Em nenhuma dessas políticas há previsão de atuação exclusiva do Estado; em todas, a diretriz é cooperar com a sociedade. Quanto à ordem econômica, é reconhecida a propriedade privada, a livre concorrência e o livre exercício da atividade econômica (artigo 170), ao tempo que o Estado é considerado agente normativo e regular da atividade econômica, exercendo funções de fiscalização, incentivo e planejamento (artigo 174). A exploração direta de atividade econômica pelo Estado está limitada aos imperativos da segurança nacional e do interesse coletivo (artigo 173), o que fundamenta o monopólio da União em certas áreas (artigo 174). Nem estatismo, nem privatismo, e sim mercado regulado, tal como pretendido pelos comunitaristas responsivos. (SCHMIDT; ARAUJO, 2012, p. 337)

O viés comunitário da Constituição Federal contempla diferentes áreas sociais, voltado a uma sociedade mais justa e igualitária, segundo ainda os autores supra citados.

É indiscutível, pois, o amparo constitucional à causa comunitária. A Constituição Federal de 1988 vem em favor da construção de uma ordem política, social e econômica marcada pelo equilíbrio Estado-comunidade-mercado, em que os cidadãos e as comunidades são protagonistas nas questões de interesse público e em que as iniciativas autônomas de comunidades particulares devem ser respeitadas pelo poder público, nos limites da legalidade. A dicotomia público/privado destoa do espírito da Constituição, que é claramente alinhado com a perspectiva da cooperação, da sinergia e complementaridade entre a ação dos entes públicos, comunitários e privados. (SCHMIDT; ARAUJO, 2012, p. 340)

Ao refletir-se sobre a necessidade de atender as insuficiências das comunidades, deve-se perceber que anuir ao Estado como único tomador de decisões, pode, em grande parte das vezes, não ser a forma mais acertada de fazê-lo, "bem como não garantir a 
aplicabilidade de princípios democráticos que consolidam o comunitarismo". (COSTA; SILVA, 2011, p. 574)

Mostrar a importância da perspectiva de uma "terceira via", visando a um ambiente adequado para o desenvolvimento e promoção de inovações tecnológicas através do trabalho em rede, é o que se pretende, mesmo que de forma introdutória, neste trabalho.

A boa sociedade é tratada por Etzioni através do tripé Estado-comunidade-mercado em equilíbrio, os quais devem estar em sinergia para criar condições adequadas.

\begin{abstract}
A terceira via etzioniana considera que o Estado tem entre suas principais atribuições a segurança pública, a saúde pública, a regulação do mercado e a proteção ambiental. O mercado é o melhor motor para produção de bens e serviços, de geração de oportunidades de trabalho, de emprego e de progresso econômico. E a comunidade é a melhor alternativa para a prestação de uma série de serviços sociais indispensáveis para a difusão de valores morais compartilhados. (SCHMIDT, 2014, p. 123-124)
\end{abstract}

$\mathrm{Na}$ linguagem de Etzioni, "as comunidades são ambientes das relações Eu-Tu, as relações baseadas em fins, enquanto o mercado é o reino das relações Eu-Isso, relações baseadas em meios". (SCHMIDT, 2014, p. 107)

Etzioni rejeita o viés de valorização unilateral da comunidade, minimizando os demais componentes do tripé:

\begin{abstract}
La Tercera Vía no ve al gobierno como el problema o como la solución sino como uno de los componentes de la buena sociedad. Tampoco ve al mercado como la raíz de todo lo bueno o de todo lo malo sino como un poderoso motor económico que debe contar con espacio suficiente para hacer su trabajo, y que, al mismo tiempo, debe ser vigilado adecuadamente. ${ }^{7}$ (ETZIONI, 2001, p. 18)
\end{abstract}

O autor aponta ainda que devemos reconhecer que os componentes se destacam entre si em áreas específicas, o que não pressupõe que realizem necessariamente o melhor trabalho. O objetivo proposto é que os três componentes possam se complementar uns aos outros: "Las comunidades han sido frecuentemente menospreciadas como factor social de importancia, inclusos por los defensores da la Tercera Vía, más pendientes de lograr un

\footnotetext{
${ }^{6}$ A terceira via aqui indicada reflete o pensamento de Amitai Etzioni, que diverge do termo utilizado por outros autores como é o caso de Anthony Giddens.

${ }^{7}$ A terceira via não vê o governo como o problema ou como a solução, apenas como um dos componentes da boa sociedade. Tampouco vê o mercado como a raiz de todo o bem ou de todo o mal, apenas como um poderoso motor econômico que deve ter espaço suficiente para fazer seu trabalho e que, ao mesmo tempo, deve ser monitorado adequadamente. (Tradução livre)
} 
adecuado equilibrio entre el estado y el mercado."8 (ETZIONI, 2001, p. 25) É fundamental para o comunitarismo o reconhecimento dos distintos papeis de cada esfera: "Estado, mercado y comunidad se diferencian por los distintos papeles que desempeñan, modificables en función de las condiciones sociales", e o equilíbrio entre eles, base da boa sociedade, pressupõe que todos cooperem entre si. (ETZIONI, 2001, p. 75)

Tal equilíbrio supõe que cada uma das partes do tripé é insubstituível em suas funções e que o comunitarismo não pretende substituir os excessos do Estado (estatismo) ou do mercado (privatismo) pela supervalorização da comunidade. $\mathrm{O}$ que o comunitarismo reivindica é o fortalecimento da comunidade, num contexto em que está depreciada pelo individualismo, e a sinergia do comunitário com o estatal e o privado. (SCHMIDT, 2014, p. 135)

Cada um dos componentes da terceira via possui importante papel a desempenhar no contexto da sociedade: o Estado é o agente promotor da iniciativa econômica e social, de forma que deve estimular os mecanismos de inovação; e o mercado é o agente responsável pela produção e oferta de bens e serviços, como consequência o gerador do emprego e da renda, sendo ele, via de regra, o agente que poderá incentivar a inovação. (ETZIONI, 2001, p. 85-86)

Para superar o modelo público-privado, o Estado deverá ir além da função de coator e absorver também um papel promotor de direitos e garantias fundamentais. (CERVI, 2013, p. 155) As comunidades, por sua vez, podem se formar nos mais diferentes espaços, próximas a instituições como as universidades ou, ainda, mais modernamente, em ambientes virtuais, por exemplo. (ETZIONI, 2001, p. 40)

As comunidades têm importante função social ao promover o bem-estar social coletivo, através de ações que oportunizam acesso igualitário a todos. São um ambiente que oportuniza o estreitamento de vínculos, especialmente por compartilharem dos mesmos interesses. Estes vínculos impulsionam a cooperação.

É justamente nesse ímpeto que aparece o movimento comunitarista, ao reforçar o aspecto humanitarista, solidário e intersubjetivo das relações sociais, propondo uma ressignificação do conceito de sociedade e comunidade, que passam a ser concebidas a partir da ótica do bem comum. (COSTA; SILVA, 2011, p. 568)

\footnotetext{
${ }^{8}$ As comunidades têm sido frequentemente menosprezadas como fator social de importância, inclusive pelos defensores da Terceira Via, mais inclinados em encontrar um adequado equilíbrio entre o Estado e o mercado. (Tradução livre)

${ }^{9}$ Estado, mercado e comunidade se diferenciam pelos distintos papéis que desempenham, modificáveis em função das condições sociais. (Tradução livre)
} 
Na visão de Etzioni, a atual economia do conhecimento possui potencial para reduzir a escassez e aumentar a justiça social, o que não tem sido explorado de forma satisfatória.

\begin{abstract}
Se ha hablado mucho, con acierto, de la importancia de alentar la transación a una economía basada en el conocimiento. Se dice que esta transformación - que conlleva priorizar las inversiones tanto en las personas (vía educación y formación permanente a lo largo de toda la vida) como en tecnología - es esencial para la prosperidad. También puede ser un buen camino de reducción de trabajos serviles y un modo de incrementar el número de empleos estimulantes, compatibles con la vida familiar y con el medio ambiente. Pero, sorprendentemente, se ha prestado poca atención a una de las características de la economía basada en el conocimiento que por sí misma justifica importantes inversiones: su potencial para reducir la escasez y para aumentar la justicia social. ${ }^{10}$ (Etzioni, 2001, p. 89-90)
\end{abstract}

O conhecimento enquanto recurso difere-se muito com relação a outros tipos de recursos, como os financeiros, por exemplo, que por sua vez são escassos. O pressuposto de que o conhecimento pode ser compartilhado ilimitadamente promove maiores possibilidades de sua disseminação, não se limitando a espaços territoriais. Salienta Etzioni (2001, p. 9091) que "aunque no todo el conocimiento puede ser compartido de esta forma, sí puede hacerse, cada vez más, con un número creciente de nuevos bienes"11.

Os mecanismos de proteção do conhecimento, através do sistema de propriedade intelectual, devem ser auxiliares no incentivo ao desenvolvimento tecnológico, ou ainda, na visão de Etzioni (2011, p. 91):

Es incuestionable que hay que afrontar problemas referentes a los derechos de patente y de propiedad intelectual, pero, en cualquier caso, y sin pasa por alto esa cuestión, existe un amplio espectro de conocimientos que pueden compartirse legalmente mediante este nuevo y facinante procedimiento, incluidos numerosos libros, músicas y obras de arte cuyos derechos de autor han expirado y están considerados de derecho público. ${ }^{12}$

\footnotetext{
10 Tem-se conversado muito, com razão, sobre a importância de incentivar a transação para uma economia baseada no conhecimento. Diz-se que esta transformação - que envolve priorizar investimentos tanto nas pessoas (através de educação e formação permanente ao longo de toda a vida) como na tecnologia - é essencial para a prosperidade. Também pode ser um bom caminho para redução de trabalhos servis e uma maneira de incrementar o número de empregos estimulantes, compatíveis com a vida familiar e com o meio ambiente. Mas, surpreendentemente, tem-se prestado pouca atenção a uma das características da economia baseada no conhecimento que por si só justifica importantes investimentos: seu potencial para reduzir a escassez e aumentar a justiça social. (Tradução livre)

${ }^{11}$ Embora nem todo o conhecimento possa ser compartilhado desta forma, pode-se fazê-lo, cada vez mais, com um número crescente de novos bens. (Tradução livre)

12 É inquestionável que existem problemas referentes aos direitos de patente e de propriedade intelectual, porém, em qualquer caso, e sem ignorar esta questão, existe um amplo espectro de conhecimentos que podem ser compartilhados legalmente através deste novo e fascinante procedimento, incluindo numerosos livros, músicas e obras de arte cujos direitos autorais tenham expirado e estão consideradas de direito público. (Tradução livre)
} 
Etzioni (2001, p. 92) destaca que quanto mais criarmos condições favoráveis para o acesso de todos a uma economia baseada no conhecimento, mais perto estaremos de viver em uma sociedade com menos escassez, tornando-se consequentemente uma sociedade mais igualitária.

Tendo presente a "bagagem moral da sociedade", Etzioni ressalta que para que alcancemos uma "boa sociedade" é indispensável o equilíbrio entre Estado, comunidade e setor privado (mercado). (ADÁN, 2001, p. 10)

Desta forma, em suma, pode-se afirmar que a sociedade adequada é aquela que apresenta condições que promovam a igualdade entre todos os seus membros, através de ações do Estado, do mercado e das comunidades.

\section{As universidades comunitárias como ambientes de redes de inovação}

As universidades comunitárias, enquanto organizações privadas sem fins lucrativos, são orientadas pelos valores próprios das comunidades e podem ser consideradas como um exemplo de organizações adequadas à cooperação própria do modelo híbrido da terceira via, cujo objetivo prevê a superação do modelo tradicional de público-privado, criando um modelo híbrido em políticas públicas com presença igualitária entre Estado, mercado e comunidade.

Sob esta ótica, tendo em vista o favorável ambiente criado em uma comunidade, muitas empresas de base tecnológica tendem a se aproximar ou introduzirem-se em organizações como as incubadoras de empresas com vínculo a universidades comunitárias, criando assim uma rede de especialistas na busca da inovação. Segundo Almeida,

\footnotetext{
As incubadoras começaram a surgir no Brasil em meados dos anos 1980, fortalecendo-se na década seguinte. Inicialmente ligadas a políticas de desenvolvimento local e regional, muitas incubadoras estavam vinculadas a prefeituras e governos estaduais; posteriormente, as universidades passaram a ser as principais promotoras das incubadoras, especialmente aquelas de base tecnológica, voltadas à inovação. (ALMEIDA, 2014, p. 78)
}

Para Albagli e Maciel (2004, p. 11), as incubadoras criam interações locais, onde “desenvolve-se um conhecimento coletivo, o qual é diferenciado e desigualmente distribuído, podendo ou não constituir importante fonte de dinamismo para aquele ambiente", qualificando-se ainda como um ambiente benéfico à troca de conhecimento, 
baseado especialmente na "existência de uma base social e cultural comum que dá o sentido de identidade e de pertencimento".

Tidd, Bessant e Pavitt (2008) sustentam que grande parte dos processos de inovação consistem na adaptação e configuração do que anteriormente havia sido desenvolvido ou, ainda, ampliando a promoção da inovação através do compartilhamento do saber. Inovar envolve riscos, e estes podem ser melhor suportados, especialmente por pequenas empresas, através de conglomerados industriais. Assim como a sinergia necessária entre os componentes da terceira via, o conhecimento coletivo criado a partir das incubadoras não se refere somente a partir da soma dos conhecimentos individuais, mas "resulta das sinergias geradas a partir dos vários tipos de interação; e altera-se inclusive na sua interseção com a circulação globalizada de informação e conhecimento.” (ALBAGLI; MACIEL, 2004, p. 11)

As incubadoras permitem conexões entre as empresas ali instaladas, junto a outros componentes como o Estado e a comunidade, criando assim uma rede de inovação. "A participação em redes de inovação pode ajudar empresas a ter novas ideias e fazer combinações criativas. Estudos sobre criatividade reconhecem que o processo envolve fazer associações.” (TIDD; BESSANT; PAVITT, 2008, p. 73)

O objetivo geral das incubadoras de base tecnológica é auxiliar as empresas nas barreiras de entrada e manutenção no mercado. Ao pensarmos as incubadoras enquanto redes, temos que as "redes de inovação duradouras podem criar a capacidade de sobreviver a grandes ondas de mudança no cenário econômico e tecnológico.” (TIDD; BESSANT; PAVITT, 2008, p. 75)

Tigre (2006, p. 137) acrescenta neste sentido que:

O ambiente geográfico e institucional no qual se localizam as empresas exerce grande influência na capacidade de inovação. [..] A difusão do conhecimento tácito é facilitada pela proximidade espacial, devido às oportunidades de aprendizado por interação entre agentes econômicos e instituições de ensino e pesquisa.

Historicamente, segundo Almeida (2014, p. 29), as redes que possibilitam a colaboração entre seus interlocutores auxiliaram para acelerar o processo inovativo, mostrando-se como valoroso fator para o êxito competitivo das empresas. A formação das redes emerge das relações preexistentes, variando-se de acordo com a realidade social. As redes são essencialmente valorizadas como ambientes que permitem o compartilhamento do conhecimento, uma vez que este é um dos maiores desafios da contemporaneidade. É através 
do trabalho em rede que o compartilhamento do saber se torna mais proveitoso. (TOMAÉL; ALCARÁ; DI CHIARA, 2005, p. 93-94)

\begin{abstract}
A inovação requer o desenvolvimento e a conservação desta rede como uma força aberta e de mútua colaboração. A gestão de parcerias eficientes na empresa e com clientes, fornecedores, consultores e todos aqueles com alguma capacidade de ajudá-la a se manter inovadora constitui um dos elementos centrais da inovação. (DAVILA; EPSTEIN; SHELTON, 2007, p. 43)
\end{abstract}

O processo de aprendizagem incita a inovação, é interativo e necessita de relações entre os seus participantes. Tais relações podem ser vistas como redes e necessitam da participação tanto dos agentes internos, tais como os funcionários de uma empresa, como de agentes externos, tais como universidades. (TOMAÉL; ALCARÁ; DI CHIARA, 2005, p. 100-101) Tomaél (2008, p. 4) destaca que os benefícios para a atuação em redes por parte das organizações variam desde construção do conhecimento até o desenvolvimento tecnológico, acrescentando ainda que:

\footnotetext{
A eficiência, a inovação e a satisfação decorrentes dessas redes possibilitam o crescimento empresarial e o desenvolvimento de uma cultura de cooperação, principalmente para as empresas baseadas em conhecimento que têm como foco promover o conhecimento e a especialização dos empregados e criar redes internas dessas fontes humanas do conhecimento.
}

Diversas podem ser as motivações que levam à criação de redes, mas geralmente estão associadas às possibilidades que a rede traz enquanto conjunto de atores e possibilidades. O CGEE (2006, p. 33) faz destaque para a integração de esforços e interesses, sejam eles políticos, acadêmicos ou industriais, elencando as seguintes motivações: proporcionar maior mobilização, integração e coordenação de equipes de pesquisadores e técnicos; propiciar e incrementar a colaboração interinstitucional; articular esforços e produzir sinergias entre as esferas pública e privada; diversificar as instituições que apoiam e financiam as atividades de pesquisa; induzir a busca de novas parcerias, tendo por objetivo o aumento da eficiência e da competitividade institucional; estimular as equipes a produzirem um sistema de acesso comum aos dados produzidos na pesquisa; aumentar o apoio a novas áreas do conhecimento e à percepção para a importância do trabalho interdisciplinar; e, aproveitar a infraestrutura de pesquisa existente.

Em concordância com tais motivos, percebe-se que a universidade possui grande potencial para o auxílio no desenvolvimento econômico regional. Florida (2011, p. 292) frisa 
que seu papel é mais amplo do que a função estritamente acadêmica, para além da teoria que "supõe uma relação causal necessária entre a pesquisa acadêmica, a inovação comercial e uma rede em contínua expansão de empresas recém-criadas", uma posição "ingênua e mecanicista da contribuição universitária para o desenvolvimento econômico". Assim,

\begin{abstract}
Não restam dúvidas de que a universidade é uma instituição essencial da economia criativa, mas muitos não compreendem o papel multifacetado que ela desempenha. Ela não está lá só para produzir projetos de pesquisa que possam virar empresas. Para que contribua de modo eficaz para o crescimento regional, a universidade precisa desempenhar três papéis inter-relacionados que espelham os 3 Ts de lugares criativos - tecnologia, talento e tolerância. (FLORIDA, 2011, p. 292)
\end{abstract}

As universidades auxiliam no desenvolvimento qualitativo das comunidades em que estão inseridas. Ao explicitar suas Teorias dos 3Ts, Florida (2011, p. 292) pontua suas funções da seguinte forma: Tecnologia - as universidades são centros para a pesquisa de ponta em campos que vão do software à biotecnologia, além de gerarem novas tecnologias e empresas spin-off; Talento - as universidades são extremamente eficazes em atrair talentos, e seu efeito é realmente magnético; ao atrair cientistas e pesquisadores eminentes, elas também captam alunos, geram empresas spin-off e estimulam outras empresas a se fixar nas proximidades, provocando um ciclo de crescimento que se autoalimenta; e Tolerância as universidades também contribuem para a criação de uma atmosfera humana progressista, aberta e tolerante, o que ajuda a atrair e reter integrantes da classe criativa.

O papel da universidade no fomento à inovação tecnológica é melhor compreendido na perspectiva da terceira via. O Estado precisa criar políticas que estimulem a articulação dos diversos agentes, o mercado precisa facilitar a incorporação das inovações no processo produtivo e a comunidade é fundamental para proporcionar valores que orientem a inovação ao bem comum. Desta forma, o ciclo estará completo, superando-se a dicotomia públicoprivado e criando-se possibilidades para alcançar uma comunidade mais justa e igualitária.

\title{
5. Considerações Finais
}

Buscou-se demonstrar a relação entre a possibilidade de criação de novas tecnologias através do viés do comunitarismo responsivo defendido especialmente pela linha do sociólogo Amitai Etzioni. Num primeiro momento foi possível perceber a existência de políticas públicas no Brasil voltadas a ciência, tecnologia e inovação, oriundas da última década. Tais ações mostram-se necessárias para que o país estimule o desenvolvimento de 
novas tecnologias e crie um ambiente favorável a promoção destas, tornando-se assim representativo em termos mundiais. Além disso, se buscou destacar a importância da inovação no contexto da atual sociedade do conhecimento.

Num segundo momento apresenta-se o comunitarismo responsivo como corrente viável junto ao desenvolvimento da inovação, uma vez que este prevê a lógica de uma relação equilibrada entre o Estado, a comunidade e o mercado, onde todos ganham nesta relação. Sob este olhar destacamos o importante papel desempenhado pelo Estado, em criar os ambientes favoráveis para o desenvolvimento de novas tecnologias, o mercado para estimular a produção de bens e serviços e movimentar a economia dando condições aos cidadãos para se inserirem no campo econômico, e por fim a comunidade, ambiente onde o trabalho compartilhado pode gerar frutos e resultados.

Por fim, destacou-se as redes de inovação vinculadas a universidades comunitárias, cujos ambientes que a compõem representam as premissas da corrente comunitarista. Especificamente neste caso utiliza-se as incubadoras de empresas, que possibilitam o trabalho conjunto de diferentes unidades, associadas com base em premissas comunitárias, e que conciliam esforços em busca de um objetivo maior, no caso, o desenvolvimento de novas tecnologias.

\section{Referências}

ADÁN, José Perez. Prólogo. ETZIONI, Amitai. La tercera vía hacia uma buena sociedade: propuestas desde el comunitarismo. Sagasta: Trotta, 2000.

ALBAGLI, S.; MACIEL, M. L. Informação e conhecimento na inovação e no desenvolvimento local. Ci. Inf., Brasília, v. 33, n. 3, p. 9-16, set./dez. 2004.

ALMEIDA, Marilis Lemos de. Rede de inovação: a articulação de estado, empresa e universidade. Porto Alegre: UFRGS, 2014.

ASSOCIAÇÃO NACIONAL DE ENTIDADES PROMOTORAS DE EMPREENDIMENTOS DE TECNOLOGIAS AVANÇADAS (Anprotec). Glossário dinâmico de termos na área de Tecnópolis, Parques Tecnológicos e Incubadoras de Empresas. Brasília: Sebrae, 2002.

BOFF, S. O.; TEIXEIRA, A. H. Políticas públicas para as inovações tecnológicas como meio de fomento ao desenvolvimento nacional. In: REIS, J. R. et al. As políticas públicas no constitucionalismo contemporâneo. t.3. Santa Cruz do Sul: EDUNISC, 2011.

BRASIL. Constituição (1988). Constituição da República Federativa do Brasil. Brasília, DF: Senado Federal, 1988. 
BRASIL. Lei n. 10.973, de 2 de dezembro de 2004. Dispõe sobre incentivos à inovação e à pesquisa científica e tecnológica no ambiente produtivo e dá outras providências. Disponível em: <http://www.planalto.gov.br/ccivil_03/_Ato20042006/2004/Lei/L10.973.htm>. Acesso em: 20 out. 2015.

BRASIL. Ministério da Ciência, Tecnologia e Inovação (MCTI). Apresenta informações gerais sobre o marco legal da inovação. Disponível em: <http://www.mct.gov.br/index.php/content/view/4949/Informacoes_Gerais.html>. Acesso em: 20 out. 2015.

BRASIL. Ministério das Comunicações. Apresenta informações sobre inovação tecnológica. Disponível em: <http://www.mc.gov.br/acoes-e-programas/inovacaotecnologica>. Acesso em: 23 out. 2015.

Centro de Gestão e Estudos Estratégicos (CGEE). Rede de Inovação da Biodiversidade da Amazônia. Brasília: CGEE, 2006.

CERVI, Jacson Roberto. As intersecções jurídicas entre o público e o privado e comunitarismo responsivo sob a ótica constitucional. In: REIS, J. R.; CERQUEIRA, K. L. (Org.) Intersecções jurídicas entre o público e o privado. Santa Cruz do Sul: IPR, 2013.

COSTA, M. M. M.; SILVA, L. O comunitarismo como mecanismo de Potencialização da participação política cidadã: uma alternativa em face da crise de legitimidade do estado contemporâneo. In: REIS, J. R. et al. As políticas públicas no constitucionalismo contemporâneo. t.3. Santa Cruz do Sul: EDUNISC,2011.

DAVILA, T.; EPSTEIN, M. J.; SHEKTON, R. As regras da inovação. Porto Alegre: Bookman, 2007.

DUTTA, S.; LANVIN, B.; WUNSCH-VINCENT, S. (Edit.) The Global Innovation Index 2015: Effective Innovation Policies for Development. Geneva: WIPO, 2015.

. The Global Innovation Index 2016: Effective Innovation Policies for Development. Geneva: WIPO, 2016.

DZIEKANIAK, G.; ROVER, A. Sociedade do Conhecimento: características, demandas e requisitos. Revista de Informação, n. 5, v. 12, out. 2011. Disponível em < http://www.dgz.org.br/out11/Art_01.htm>. Acesso em: 02 nov. 2015.

ETZIONI, Amitai. La tercera vía hacia una buena sociedade: propuestas desde el comunitarismo. Sagasta: Trotta, 2001.

La nueva regla de oro: comunidad y moralidad en una sociedad democrática. Barcelona: Paidós, 1999.

Organizações modernas. 6.ed. São Paulo: Pioneira, 1980. 
FLORIDA, Richard. A ascensão da classe criativa: e seu papel na transformação do trabaho, do lazer, da comunidade e do cotidiano. Porto Alegre: L\&PM Editores, 2011.

Instituto Brasileiro de Geografia e Estatística (IBGE). Pesquisa de Inovação (PINTEC) 2011. Disponível em <http://www.pintec.ibge.gov.br/> . Acesso em 23 ago. 2015.

MATTOS, J. R. L.; GUIMARÃES, L. S. Gestão da Inovação Tecnológica: uma abordagem prática. São Paulo: Saraiva, 2005.

ORGANIZAÇÃO PARA A COOPERAÇÃO E O DESENVOLVIMENTO ECONÔMICO (OCDE). Manual de Frascati: Metodologia proposta para levantamentos sobre pesquisa e desenvolvimento experimental. [S.1.]: F-INICIATIVAS P+D+I, 2013.

SCHMIDT, João Pedro. Para entender as políticas públicas: aspectos conceituais e metodológicos. In: REIS, J. R.; LEAL, R. G. (Org.) t al. Direitos Sociais e políticas públicas: desafios contemporâneos. t.8. Santa Cruz do Sul: EDUNISC,2008.

Amitai Etzioni e o paradigma comunitarista: da sociologia das organizações ao comunitarismo responsivo. Lua Nova, São Paulo, n. 93, p. 93-138, set./dez. 2014.

Comunitarismo e capital social: convergências. Revista Debates, Porto Alegre, n. 2, v. 9, p. 55-75, mai./ago. 2015.

; ARAUJO, N. Comunidade e comunitarismo na Constituição Federal e na legislação brasileira. Novos Estudos Jurídicos, v. 17, n. 3, p. 327-344, set./dez. 2012.

TIDD, J.; BESSANT, J.; PAVITT, K. Gestão da inovação. 3.ed. Porto Alegre: Bookman, 2008.

TIGRE, Paulo Bastos. Gestão da inovação: a economia da tecnologia no Brasil. Rio de Janeiro: Elsevier, 2006.

TOMAÉL, Maria Inês. Redes de conhecimento. Revista de Ciência da Informação, v. 9, n.2, abr. 2008. Disponível em < http://www.dgz.org.br/abr08/Art_04.htm>. Acesso em: 27 ago. 2015.

.; AlCARÁ, A. R.; DI CHIARA, I. G., Das redes sociais à inovação. Ci. Inf., Brasília, v. 34, n. 2, p. 93-104, mai./ago. 2005. 